\title{
Bureaucracy in general practice: time to halt a proliferating malaise
}

Almost all of us who work in health care will be aware that the past few years have seen a significant rise in bureaucracy. The medical and nursing professions have had to absorb a raft of clinical guidelines and protocols, and primary care trusts (PCTs) expect practices to have their own guidelines on virtually all matters affecting administration, employment law, training and disciplinary procedures. In this essay we shall argue that this bureaucracy is excessive, and part of a concerted drive to undermine professional values and morale without offering any extra protection to patients. We also argue that regulatory bodies have colluded with this, and should instead take a more proactive lead in stemming this culture.

In the interest of fairness we acknowledge that not all recommendations for how primary care works are necessarily bad. Few would argue against staff being trained in resuscitation or child protection, in preparation for those rare events when prompt action may save a life. The tenets of evidence-based medicine ${ }^{1}$ upon which the Quality and Outcomes Framework $(\mathrm{QOF})^{2}$ rests are broadly sound, although the jury is still out as to whether NICE will consolidate any gains now that they are overseeing this. However, our recent experience is that many recommendations make no concession to common sense; the following are but three examples. Our local PCT insists that consent for childhood immunisations be in a much greater detail than established national guidelines. ${ }^{3}$ Non-clinical chaperones now require full training, at a cost of $£ 80$ and a day away from work. Choose and Book has been implemented, but is a tedious exercise of doubtful benefit to patients, and has certainly distanced GPs from our consultant colleagues.

This trend has been occurring for many years; however, certain pivotal events have accelerated the process. Harold Shipman certainly had much to answer for, yet one of many ironies about his case is that Shipman was an extremely popular doctor. Personable, readily available, and keen on home visiting, he ticked all the right boxes and would have scored highly on patient surveys, weighted as they are to hostelry rather than clinical outcomes. When Shipman's murderous ways were discovered, the case became the subject of a public inquiry, led by Dame Janet Smith. However, her report was flawed; its criticism of the General Medical Council (GMC) being excessive. ${ }^{4}$ Faced with this the GMC could have responded robustly, placating public concern by fine-tuning an essentially sound regulatory role, while stating that such freakish, determined criminality as Shipman's could not always be legislated for: Shipman was no more representative of GPs than Beverley Allitt was of nurses. Colleagues had warned against over-reaction and the creation of a punitive environment; ${ }^{5}$ sadly, this went unheeded. In the years that followed, the GMC has perpetrated the worst excesses of bureaucracy. It has swelled its own ranks by recruiting a large number of lay members, something one could never imagine, for example, the Law Society doing. It has implemented far more detailed cremation forms, and concern has now been raised about the number of referrals made to coroners for postmortem purely because of defensive practice. ${ }^{6}$ With astonishing insensitivity, it has also decided to massively increase its annual retention fee this year, although most members ask no more from it than to maintain their name on a register. It is not the only healthcare organisation with an inflated sense of its own worth. The Nursing and Midwifery Council (NMC) and Royal College of Nursing (RCN) charge $£ 76$ and £189.67 respectively, all of which have risen well above the official rate of inflation in recent years, and nurses are even less likely than doctors to be rich people.

The GMC displays the hallmarks of a paranoid Third World dictatorship in how it seeks out (usually non-existent) problems; indeed, Shipman appears to have been a timely pretext to pursuing a pre-existing authoritarian agenda. It has turned its attention to medical students, joining forces with the Medical Schools Council to target what they consider inappropriate behaviour at an early stage. ${ }^{7}$ Yet doctors, and other healthcare professionals, are no more or less perfect than any other humans, and had such scrutiny been applied to previous generations we may never have had some of our most able figures. Florence Nightingale had a fierce devotion to public duty, but was a notorious snob. ${ }^{8}$ Albert Schweitzer, who practised in what is now Gabon in West Africa, had genuine affection for black Africans which was, nonetheless, couched in paternalistic terms. ${ }^{9}$ Marie Stopes, a pioneer of women's sexual health, followed two failed marriages by taking a coterie of much younger lovers, and was a lifelong advocate of eugenics. ${ }^{10}$ Christiaan Barnard, the South African surgeon who performed the first successful human-tohuman heart transplant in 1967, married and divorced three times and remained an amiable philanderer all his adult life. ${ }^{11}$ More mundanely, those of us of a certain vintage remember when a campus-like atmosphere thrived in hospital social clubs and staff residences, and medical students, junior doctors, and nurses would mingle freely. Yet this would almost certainly fall foul of today's thought police, but then so too would Nightingale, Schweitzer, Stopes, and Barnard.

The government is also culpable in such developments. There is no more telling indictment of the values which govern our times than the differential treatment of the professions and the financial services industry. While the former are weighed down by bureaucracy, the latter have, until recently, been the beneficiaries of (the now infamous) 'light touch', despite a culture of greed and excess that has led to all which now ails us. ${ }^{12}$ It has been said that in the ideological battle between right and left, the right has won on the economy and the 
left in social policy. Such a situation would have been paradoxical to earlier generations; however, the sub-plot is that the two sides have struck a deal with each other, Labour itself being the apotheosis of this trend. The fusion of consumer capitalism and liberal-left social values permeates national life, particularly in politics, the media, arts, and entertainment. A particularly malign result has been the emergence of an elite which preaches values such as equality and inclusiveness, while being as adept as any previous elite as securing privileges for themselves, possibly more so since they cunningly deny the very existence of elitism. ${ }^{13}$ Because the values they espouse are anti-intellectual, the net effect is to undermine professionals in general. In this respect health care and education are particularly vulnerable, as the majority of provision in the UK is via the public sector. In a mature democracy, public policy should be formulated from a consensus of opinion; however, in recent years dogma and political correctness appear to have supplanted reasoned debate. With Stalinist precision, a remarkably consistent 3-stage plan has evolved when implementing healthcare bureaucracy. Firstly, a myth is created. Secondly, it is repeated frequently enough to foment doubt among the public, and eventually health professionals. Thirdly, remedial action in the form of populist measures is implemented. The following are but three examples:

- Doctors are perceived as a socioeconomically privileged group prone to the prejudices of that ilk. In reality, assuming (with some justification) that females and ethnic minorities constitute the historically oppressed, these groups are overrepresented in medicine to such an extent that the most likely graduate from a UK medical school is a young woman of Indian descent. ${ }^{14} \mathrm{~A}$ chance to foist equal opportunities training is thus created.
- Doctors have historically been paternalistic and didactic in their interaction with patients. As a result, patient-centredness looms large in medical education. Yet taken to extremes this can be just as damaging. For example, the discredited research by Andrew Wakefield and his colleagues ${ }^{15}$ casting doubt on the MMR vaccine has led many parents to opt out, exposing their children and others to the risks of measles.

- An 11-hour working day for a mid-sized surgery is judged too short, and compared unfavourably with the local supermarket. As a result the partners agree to work extended hours under a Local Enhanced Scheme (LES), for pin money, which may even run out next year. The same public discourse which is critical of doctors' availability continues to lament the long hours culture, and wax lyrical about the importance of quality time with the family.

Government policy in other domains follows a similar pattern, all of which has the potential to affect health care. Faced with a growing problem of alcohol-related health and social problems, the government ignored professional advice to restrict availability ${ }^{16}$ and opted for 24hour licensing, ${ }^{17}$ a clear genuflection to commercial interest (and, interestingly, a denial of reality rather than creation of a myth)..$^{18}$ Another example of muddled thinking is the pursuit of multi-culturalism in education. Many commentators, including some who are themselves foreign-born, have expressed concern that far from promoting assimilation and social cohesion, this is having the opposite effect, encouraging alienation and segregation among the British-born children of the poorest and most disaffected immigrants. ${ }^{19,20}$ However, this disastrous policy continues.

A pathology is affecting the middle class, which has traditionally been the most broad-minded and inclusive social stratum. Had it been anything else, it would not have, over the years, seen its ranks swell by incomers from the working class who had done well through the professions or business. Furthermore, it has not, historically, had to choose between intellectual and material aspiration, both being integral to it. Recently, however, it appears that the former has shrunk as the latter has expanded, and the two are appearing mutually exclusive. Witness the welleducated controllers of TV channels, who feed the public with low-brow reality shows, then cite the huge viewing figures and corporate profits as the end which justifies the means. Enter any bookshop and you will see the shelves lined with hundreds of confessional celebrity autobiographies, the content of which typically follow the same repetitive, puerile litany of addictions and failed relationships. Yet educated men and women gladly ghost-write these books, taking their cut for peddling the illusion that beneath every glamour model lurks an erudite wordsmith.

This trend is relevant to health-related professions, who are steadily having their autonomy eroded and being manipulated by the government and media to fulfil their aims. Worryingly, though, professional institutions have bought into the populist agenda instead of upholding their members' traditional values. The GMC's feeble capitulation has already been chronicled. However, the British Medical Association (BMA) and the RCGP have, in turn all too readily accepted the GMC's proposals for appraisal and then revalidation, yet more tedium unlikely to root out many bad apples. A recent edition of our local medical committee (LMC) newsletter solemnly warns readers that 'the balanced scorecard will be the key method of assessing performance and monitoring it over the year' and that 'practices that fail to achieve targets set within 1 year will rapidly be receiving remedial notices - as far as this paper is 
concerned there will be only two stages to termination of contracts', (Bedfordshire and Hertfordshire Local Medical Committee Ltd, Newsletter 27, Winter 2009). This is an organisation purporting to support doctors, yet the tone could be straight from the totalitarian nightmare of George Orwell's 1984. ${ }^{21}$ One wonders where healthcare workers can turn to when in distress, and how we have allowed ourselves to reach this parlous state. We are skilled and learned people, who have often trained for over a decade before assuming our final post, and who are likely to be in public service long after most PCT bureaucrats and government ministers have returned to obscurity. Yet we fear having our reputations besmirched not for any clinical or ethical lapse, but because we have not complied with each meddlesome diktat, or have slightly alternative lifestyles or attitudes.

The most scandalous aspect of the government's penchant for creating bureaucracy within the public sector is it's sheer cost - billions of pounds of taxpayers' money, mostly raised from middle-income earners, is being squandered for no discernible gain. ${ }^{22} \mathrm{~A}$ vicious cycle has emerged where bureaucracy requires more managers, who in turn justify their own existence by ratcheting up bureaucracy. The middle tier of the PCT hierarchy is, perversely, dominated by former nurses who have acquired a quite different manner, language, and view of the world to that of their former clinical colleagues. Devoid of any clinical responsibility and enjoying the mutual support of burgeoning numbers, they are unsympathetic to the fact that frontline clinicians, who have had no increase in their own numbers nor in administrative support, have to implement these diktats on top of their busy clinical practice, which can comfortably exceed 100 patients contacts per week for a fulltime doctor or nurse. At an individual level, it is understandable why nurses leave clinical work to join PCTs, for the attractions of better pay and an easier life are obvious. However, this is also symptomatic of the misguided priorities in healthcare planning. The greatest challenge facing health care is that of rising chronic disease in an ageing population, ${ }^{23}$ not whether your practice or ours answers the phone in three or four rings, or has a policy document to 'deal with' staff members who form a romantic liaison (we jest not). Those nurses would make themselves more useful if they returned to healing the sick. By the same token, if clinical care was given due value and better paid, emigration from it would be less beguiling, and if they reigned in the number of managers the government could yet reduce its wage bill.

We are at a crossroads in health care. While much good had occurred in recent years, increased and pointless bureaucracy and the undermining of professional autonomy blights our landscape. Healthcare professionals cannot change this alone, and need the support of our regulatory bodies, unions and defence organisations. These bodies should surely have the gravitas to remain accountable to the public without acting as if the only way to do so is to hang a Sword of Damocles over their members. Above all, if we are to have a proper meritocracy, we need a culture in which common sense can prevail, and in which nonsense is given due contempt.

\section{Edin Lakasing and Heather Francis}

\section{REFERENCES}

1. Sackett DL, Rosenberg WMC, Gray JAM, et al. Evidence based medicine: what it is and what it isn't BMJ 1996; 312(7023): 71-72

2. Department of Health. Investing in general practice: the new general medical services contract. London: Department of Health, 2003.

3. Salisbury D, Ramsay M, Noakes K (eds). Immunisation against infectious disease. London: Department of Health, 2003.

4. Smith J. The Shipman Inquiry. Fifth Report Safeguarding Patients: Lessons from the past Proposals for the Future. 2004. http://www.theshipman-inquiry.org.uk/fifthreport.asp (accessed 12 Aug 2009).

5. Turner JJ. The GMC: expediency before principle GMC reform may damage the NHS (letter). BMJ 2005; 330: 252

6. Reisner $\mathrm{C}$. What are coroners and pathologists for? BMJ 2009; 338: b1355.

7. General Medical Council. Medical students: professional behaviour and fitness to practice. GMC, 2009. http://www.gmc-

uk.org/education/undergraduate/undergraduate_poli cy/professional_behaviour.asp (accessed $12 \mathrm{Aug}$ 2009).

8. Bostridge M. Florence Nightingale: the woman and her legend. London: Viking, 2008.

9. Seaver G. Albert Schweitzer - the man and his mind. London: A\&C Black, 1951

10. Lakasing E. Marie Stopes - controversial pioneer of women's sexual health. Capital Doctor 2005; 48/9: $22-23$.
11. Richmond C. Obituary: Professor Christiaan Barnard. The Independent 2001; 3 September 2001. http://www.independent.co.uk/news/obituaries/professor-christiaan-barnard-729378.html (accessed 12 Aug 2009).

12. Cable V. The storm: the world economic crisis and what it means. London: Atlantic Books, 2009.

13. Walden G. The new elites - making a career in the masses. London: Penguin Books Ltd, 2000.

14. BMA Board of Medical Education. The demography of medical schools: a discussion document. London: BMA, 2004.

15. Wakefield AJ, Murch SH, Anthony A et al. Ileallymphoid nodular hyperplasia, non-specific colitis and pervasive developmental disorder in children. Lancet 1998; 351: 637-641.

16. Academy of Medical Sciences. Calling time: the nation's drinking as a health issue. London: Academy of Medical Sciences, 2004.

17. Cabinet Office Strategy Unit. Alcohol harm reduction strategy for England. London: Strategy Unit, 2004.

18. Mirza ZA, Lakasing E. Government strategy on alcohol: time to revise legislation and implement wider interventions. Br J Gen Pract 2008; 58: 286-287.

19. Walden G. Time to emigrate? London: Gibson Square Books Ltd, 2006.

20. Alagiah G. A Home from home. London: Little, Brown, 2006

21. Orwell G. Nineteen eighty-four. A novel. London: Secker and Warburg, 1949.

22. Craig D. Plundering the public sector. London: Constable, 2006.

23. Yach D, Hawkes C, Gould CL, Hofman K. The global burden of chronic diseases - overcoming impediments to prevention and control. JAMA 2004; 291: $2616-2622$.

DOI: 10.3399/bjgp09X454241 